\title{
Hubungan antara status kesehatan gigi dengan kualitas hidup pada manula di Kecamatan Malili, Luwu Timur (The corelation between dental health status and the quality of life in the elderly in District Malili, Luwu Timur)
}

\author{
Ayub Irmadani Anwar \\ Bagian Ilmu Kesehatan Gigi Masyarakat \\ Fakultas Kedokteran Gigi, Universitas Hasanuddin \\ Makassar, Indonesia
}

\begin{abstract}
Negative impact of poor oral health on quality of life in the elderly is an important public health problem. Around the world, poor oral health in the elderly seemed to edentulous, dental caries and periodontal disease. It was reported a strong correlation between the number of teeth lost by a score of HHIP-14. This study aimed to determine the relationship of oral health and quality of life of the elderly in District of Malili, East Luwu. Pathfinder pilot survey-based study conducted in 15 villages in that district on 10-12 November 2011. The subjects were elderly people who come to the village hall, which is guided by a questionnaire interviewed and met the inclusion criteria. The results showed that the elderly average index of DMF-T at 11.11, which indicated that the oral health status was significantly positively correlated with quality of life (OHIP-14), with a correlation value of 0.170. It was concluded that the higher the value of DMF-T, the more affect the quality of life of the elderly.
\end{abstract}

Keywords: elderly, DMF-T index, quality of life

\begin{abstract}
ABSTRAK
Dampak negatif dari kesehatan mulut yang buruk terhadap kualitas hidup pada manula merupakan masalah kesehatan masyarakat yang penting. Di seluruh dunia, kesehatan mulut yang buruk pada manula tampak dengan kehilangan banyak gigi, karies gigi dan penyakit periodontal. Dilaporkan juga adanya hubungan yang kuat antara jumlah gigi yang hilang dengan skor OHIP-14. Penelitian ini dimaksudkan untuk mengetahui hubungan kesehatan mulut dengan kualitas hidup pada lansia di Kecamatan Malili, Luwu Timur. Penelitian berbasis pilot pathfinder survey dilaksanakan pada 15 desa di daerah tersebut pada tanggal 10-12 November 2011. Subjek penelitian adalah manula yang datang ke balai desa, yang diwawancarai secara terpimpin berdasarkan kuisioner dan memenuhi kriteria inklusi. Hasil penelitian adalah rata-rata indeks DMF-T manula sebesar 11,11, yang berindikasi bahwa status kesehatan gigi dan mulut secara signifikan berkorelasi positif dengan kualitas hidup (OHIP-14), dengan nilai korelasi 0,170. Disimpulkan bahwa semakin tinggi nilai DMF-T semakin tinggi pula mempengaruhi kualitas hidup manula.
\end{abstract}

Kata kunci: manula, indeks DMF-T, kualitas hidup

Koresponden: Ayub Irmadani Anwar,_E-mail: ayubanwar_mks@yahoo.com

\section{PENDAHULUAN}

Proses menua adalah proses alami yang disertai adanya penurunan kondisi fisik, psikologis maupun sosial yang berinteraksi satu sama lain. Keadaan itu cenderung menimbulkan masalah kesehatan umum maupun kesehatan jiwa secara khusus pada manula. ${ }^{1}$

Kelompok umur manula dibagi menjadi tiga, yaitu 50-65 tahun (young old), 66-85 tahun (old) dan 85 tahun ke atas (oldest old). ${ }^{2}$ Pada umumnya, setelah memasukimasa usia lanjut, sesorang akan mengalami penurunan fungsi kognitif dan psikomotor, sehingga reaksi dan perilaku manula menjadi makin lambat dan menjadi kurang cekatan. ${ }^{3}$ Secara umum penurunan tersebut akan berpengaruh pada aktivitas kehidupan sehari-hari. Masalah yang biasa dialami manula yang berhubungan dengan kesehatan fisik adalah rentan terhadap berbagai penyakit, karena berkurangnya daya tahan tubuh dalam menghadapi pengaruh dari luar. ${ }^{4}$ Meningkatnya gangguan penyakit pada manula dapat menurunkan kualitas hidup manula. ${ }^{5}$
Khusus mengenai kesehatan mulut, pada manula, jaringan penyangga gigi mengalami kemunduran sehingga gigi goyang dan mudah tanggal. Secara makroskopik, gigi mengalami perubahan bentuk dan warna seiring dengan pertambahan usia. Di Indonesia sekitar $24 \%$ manula yang berusia 65 tahun atau lebih mengalami kehilangan gigi. ${ }^{6}$ Kondisi itu merupakan ancaman terhadap kualitas hidup manula dalam menjalani kehidupan sehari-hari. Selain itu perilaku hidup sehat utamanya kesehatan gigi tidak kalah perannya mengenai cara pandang manula tentang pengaruh kesehatan mulut terhadap kualitas hidup. ${ }^{7}$ Kualitas hidup menurut World Health Organization (WHO) adalah persepsi seseorang dalam konteks budaya dan norma yang sesuai dengan tempat hidup orang tersebut serta berkaitan dengan tujuan, harapan, standar dan kepedulian selama hidupnya. ${ }^{5}$

Perlunya menilai pandangan pasien terhadap kesehatan gigi dan kemungkinan dampak kesehatan gigi di kehidupan sehari-hari, menyebabkan selama 
dekade terakhir, beberapa ahli telah mengembangkan minat dalam kedokteran gigi untuk menilai riwayat pasien yang dinilai dengan oral health related quality of life (OHRQoL). Penilaian itu merupakan konsep multidimensi yang terhubung dengan kualitas hidup terutama yang berkaitan dengan kesehatan mulut dan penyakit. Untuk manula, oral health impact profile (OHIP-14) adalah formulirsingkat yang paling sering digunakan. Kuesioner ini mengukur dampak dari masalah gigi dan yang mencakup masalah fisik, psikologis dan dimensi sosial kehidupan sehari-hari. ${ }^{7}$

Dampak negatif kesehatan mulut yang buruk terhadap kualitas hidup manula merupakan masalah kesehatan masyarakat yang penting. Di seluruh dunia, kesehatan mulut yang buruk pada manula terutama tampak dengan banyaknya gigi yang hilang, karies gigi dan penyakit periodontal. ${ }^{5}$ Perlunya memelihara kesehatanmulut tidak berhenti dengan bertambahnya usia dan melemahnya kesehatan umum. Sebaliknya, diketahui kesehatan mulut yang buruk pada manula menaikkan risiko terhadap gangguan kesehatan. ${ }^{8}$

Beberapa penelitian telah menunjukkan bahwa kondisi mulut mempunyai dampak yang negatif pada kehidupan sehari-hari terutama pada manula. Selain itu, telah dilaporkan hubungan antara jumlah gigi dan kualitas hidup yang terkait dengan kesehatan mulut. Lahti, dkk dan Nutall, dkk yang dikutip oleh Dahl, dkk juga melaporkan hubungan yang kuat antara jumlah gigi yang hilang dengan skor OHIP-14. ${ }^{7}$

Malili merupakan salah satu kecamatan di Kabupaten Luwu Timur Provinsi Sulawesi Selatan dengan luas wilayah $921,20 \mathrm{~km}^{2}$, terdiri dari 13 desa yang berstatus definitif dan dua desa berstatus UPT. Enam dari 15 desanya merupakan wilayah pantai. Selain itu, topografi wilayah Malili adalah daerah berbukit. Sepuluh dari 15 desa merupakan wilayah berbukit-bukit, sedangkan sisanya tergolong wilayah datar.Fasilitas kesehatan di Kecamatan Malili hanya dua puskesmas, 12 puskesmas pembantu, dua buah polindes, 24 posyandu, dua apotik, dan dua toko obat. Selain itu, terdapat lima tempat praktik dokter dan 10 praktikbidan. Tenaga medis yang tersedia hanya tujuh dokter, satu dokter gigi, dan 19 bidan. ${ }^{9}$ Dari profil singkat tersebut terlihat bahwa fasilitas kesehatan di Kecamatan Malili sangat minim, selain itu tenaga medis yang tersedia juga sangat sedikit.

Berdasarkan latar belakang tersebut, penelitian ini dilakukan dengan maksud untuk mengetahui hubungan kesehatan gigi (DMF-T) dengan kualitas hidup (OHIP-14) pada manula di Kecamatan Malili Kabupaten Luwu Timur.

\section{BAHAN DAN METODE}

Penelitian berbasis pilot pathfinder survey ini dilakukan di 15 desa di Kecamatan Malili Kabupaten Luwu Timur pada bulan November 2011. Subjek penelitian diambil dari manula yang datang ke 15 balai desa di Kecamatan Malili, dengan kriteria inklusi subjek manula (usia $\geq 50$ tahun) yang tidak edentulus dan tidak terbelakang mental. Sedangkan kriteria eksklusi adalah subjek yang tidak bersedia berpartisipasi. Subjek diwawancarai dengan teknik wawancara terpimpin yang mengacu pada kuisioner.

\section{Kualitas hidup}

Kualitas hidup manula diukur menggunakan penilaian OHIP-14 yang meliputi 7 domain. Domain 1 adalahketerbatasan fungsi yang meliputi kesulitan berbicara dan menikmati makanan; domain 2 adalah rasa nyeri fisik yang meliputi rasa nyeri dalam mulut dan rasa tidak nyaman ketika makan; domain 3 adalah ketidaknyamanan jiwa yang meliputi rasa cemas dan tegang; domain 4 adalah ketidaknyamanan fisik yang terdiri dari ketidakpuasan untuk makan serta rasa terganggu saat makan. Sedangkan domain 5 adalah ketidaknyamanan jiwa yang meliputi kesulitan untuk bersantai danrasa malu; domain 6 adalah keterbatasan sosial yang meliputi rasa terganggu oleh orang lain dan sulit untuk melakukan pekerjaan, dan domain 7 adalah kerugian akibat kesehatan mulut yang meliputi kehidupan tidak memuaskan dan aktivitas/seluruh pekerjaan terganggu. Masing-masing pertanyaan mempunyai lima peringkat dari peringkat 0 sampai dengan peringkat 4 , dengan kriteria berturut-turut tidak pernah $=$ tidak pernah dirasakan ada keluhan $(0)$, hampirtidak pernah = bila keluhan dirasakan hampir satu kali dalam setahun (1), kadang-kadang = bila keluhan dirasakanhampirdua kali dalam setahun (2), cukup sering = bila keluhan dirasakan hampir empat kali dalam setahun (3), dan sangat sering $=$ jika keluhan dirasakan hampir setiap bulan sekali (4). ${ }^{6,10}$

\section{Pengolahan dan analisis data}

Setelah dilakukan pengumpulan data, setiap kuisioner dievaluasi, kemudian diolah menggunakan komputerdengan program SPSS versi 16.0. Penyajian data dilakukan secara narasi dan tabel. Adanya hubungan antarvariabel diuji dengan korelasi Pearson dan Spearman; sedangkan perbedaan antar variabel diuji dengan uji-T tidak berpasangan pada tingkat kemaknaan sebesar $5 \%$.

\section{HASIL}

Didapatkan subjek penelitian sebanyak 218 orang dengan karakteristik yang tampak pada tabel 1. atarata usia sampel dari 50-92 tahun adalah 60,16 tahun. Mengenai jumlah gigi yang tersisa, paling banyak responden yang bergigi 21-28 dialami 108 orang. 
Tabel 1 Karakteristik responden berdasar jenis kelamin, usia dan jumlah gigi

\begin{tabular}{lccc}
\hline Karakteristik & $\mathrm{n}$ & $\%$ & Rerata (SD) \\
\hline Jenis Kelamin & & & \\
$\quad$ Laki-laki & 103 & $47,2 \%$ & - \\
$\quad$ Perempuan & 115 & $52,8 \%$ & - \\
Usia (50-92 tahun) & 218 & $100 \%$ & $60,16(9,84)$ \\
Jumlah gigi & & & - \\
$1-10$ & 50 & $22,9 \%$ & - \\
$11-20$ & 60 & $27,5 \%$ & - \\
$21-28$ & 108 & $49,5 \%$ & - \\
\hline
\end{tabular}

Tabel 2 Data responden berdasarkan skorDMF-T

\begin{tabular}{lccc}
\hline Karakteristik & $\mathrm{n}$ & $\%$ & Rata-rata (SD) \\
\hline Decayed teeth & & & $3,34(3,70)$ \\
$\quad$ Ada & 165 & $75,7 \%$ & \\
$\quad$ Tidak ada & 53 & $24,3 \%$ & \\
Missing teeth & & & $7,76(7,56)$ \\
$\quad$ Ada & 188 & $86,2 \%$ & \\
$\quad$ Tidak ada & 30 & $13,8 \%$ & \\
Filled teeth & & & $0,02(0,16)$ \\
$\quad$ Ada & 3 & $1,4 \%$ & \\
$\quad$ Tidak ada & 215 & $98,6 \%$ & \\
Indeks DMF-T & & & $11,11(8,54)$ \\
\hline
\end{tabular}

Dari tabel 2 didapatkan data responden yang mengalami decay adalah 165 orang $(75,7 \%)$ dengan rata-rata 3,34 . Selain itu, manula yang mengalami missing berjumlah 188 orang $(86,2 \%)$, dengan ratarata 7,76. Sementara responden yang memiliki filling berjumlah tiga orang $(1,4 \%)$, dengan rata-rata 0,02 . Rata-rata indeks DMF-T adalah 11,11.

Dari tabel 3, diketahui jumlah gigi secara bermakna berkorelasi negatif dengan indeks DMF-T maupun skor OHIP-14, dan usia secara bermakna berkorelasi positif dengan indeks DMF-T.

Dari tabel 4 , terlihat bahwa skor rata-rata OHIP14 pada domain 1 adalah 2,48 , domain 2 adalah 3,17 , domain 3 adalah 1,43, domain 4 adalah 2,96, domain 5 adalah 1,34, domain 6 adalah 1,27, dan domain 7 adalah 1,17 . Sedangkan skor total rata-rata OHIP-14 adalah 13,82 .

Tabel 3 Skor rata-rata DMF-T dan OHIP-14 berdasarkan jenis kelamin, usia dan jumlah gigi yang tersisa

\begin{tabular}{|c|c|c|}
\hline $\begin{array}{c}\text { Karakteristik } \\
\text { Responden }\end{array}$ & DMF-T (SD) & OHIP-14 (SD) \\
\hline \multicolumn{3}{|l|}{ Jenis Kelamin } \\
\hline Laki-laki & $11,09(8,87)$ & $13,70(10,55)$ \\
\hline Perempuan & $11,14(8,28)$ & $13,94(9,77)$ \\
\hline Nilai $p^{(a)}$ & 0,321 & 0,865 \\
\hline \multicolumn{3}{|l|}{ Usia } \\
\hline $50-92$ & $11,11(8,54)$ & $13,82(10,12)$ \\
\hline Nilai p (r) ${ }^{(b)}$ & $0,000^{*}(0,261)$ & $0,486(0,047)$ \\
\hline \multicolumn{3}{|l|}{ Jumlah gigi } \\
\hline $1-10$ & $18,68(9,64)$ & $16,78(11,36)$ \\
\hline $11-20$ & $14,07(7,14)$ & $13,90(10,83)$ \\
\hline $21-28$ & $5,97(4,37)$ & $12,42(8,82)$ \\
\hline Nilai p (r) ${ }^{(\mathrm{c})}$ & $0,000^{*}(-0,591)$ & $0,039^{*}(-0,140)$ \\
\hline $\begin{array}{l}\mathrm{SD}=\text { standar d } \\
\text { berpasangan; }\end{array}$ & bermakna $(\mathrm{p}<$ & 5); (a) uji-t tidak \\
\hline
\end{tabular}

Dari tabel 5, indeks decay didapatkan secara bermakna berkorelasi positif pada domain 6 , indeks missing didapatkan secara bermakna berkorelasi positif baik dengan domain 4 , domain 5 dan domain 7. Indeks DMF-T diketahui berkorelasi positif secara bermakna pada domain 4 sampai domain 7 dan kualitas hidup secara keseluruhan.

\section{PEMBAHASAN}

Dari 218 responden yang memenuhi kriteria inklusi dan ekslusi, jumlah laki-laki lebih sedikit dibandingkan dengan perempuan. Distribusi ini sama seperti yang dilaporkan Ingle, dkk, ${ }^{11}$ bahwa

Tabel 4 Distribusi responden berdasarkan indeks OHIP-14

\begin{tabular}{|c|c|c|c|c|c|c|c|}
\hline \multirow{2}{*}{ OHIP-14 } & \multirow{2}{*}{ Rata-rata (SD) } & & 0 & 1 & 2 & 3 & 4 \\
\hline & & & $\mathrm{n}(\%)$ & $\mathrm{n}(\%)$ & $\mathrm{n}(\%)$ & $\mathrm{n}(\%)$ & $\mathrm{n}(\%)$ \\
\hline \multirow[t]{2}{*}{ Domain 1} & $2,48(2,13)$ & 1 & $106(48,6 \%)$ & $40(18,3 \%)$ & $43(19,7 \%)$ & $27(12,4 \%)$ & $2(0,9 \%)$ \\
\hline & & 2 & $77(35,3 \%)$ & $26(11,9 \%)$ & $65(29,8 \%)$ & $31(14,2 \%)$ & $19(8,7 \%)$ \\
\hline \multirow[t]{2}{*}{ Domain 2} & $3,17(2,06)$ & 1 & $62(28,4 \%)$ & $36(16,5 \%)$ & $68(31,2 \%)$ & $45(20,6 \%)$ & $7(3,2 \%)$ \\
\hline & & 2 & $54(24,8 \%)$ & $35(16,1 \%)$ & $77(35,3 \%)$ & $41(18,8 \%)$ & $11(5,0 \%)$ \\
\hline \multirow[t]{2}{*}{ Domain 3} & $1,43(1,79)$ & 1 & $118(54,1 \%)$ & $43(19,7 \%)$ & $19(8,7 \%)$ & $32(14,7 \%)$ & $6(2,8 \%)$ \\
\hline & & 2 & $153(67,7 \%)$ & $37(16,4 \%)$ & $22(9,7 \%)$ & $8(3,5 \%)$ & $6(2,7 \%)$ \\
\hline \multirow[t]{2}{*}{ Domain 4} & $2,96(2,29)$ & 1 & $73(33,5 \%)$ & $42(19,3 \%)$ & $56(25,7 \%)$ & $40(18,3 \%)$ & $7(3,2 \%)$ \\
\hline & & 2 & $62(28,4 \%)$ & $34(15,6 \%)$ & $67(30,7 \%)$ & $45(20,6 \%)$ & $10(4,6 \%)$ \\
\hline \multirow[t]{2}{*}{ Domain 5} & $1,34(1,80)$ & 1 & $133(61,0 \%)$ & $32(14,7 \%)$ & $35(16,1 \%)$ & $18(8,3 \%)$ & $0(0,0 \%)$ \\
\hline & & 2 & $141(64,7 \%)$ & $36(16,5 \%)$ & $25(11,5 \%)$ & $13(6,0 \%)$ & $3(1,4 \%)$ \\
\hline \multirow[t]{2}{*}{ Domain 6} & $1,27(1,71)$ & 1 & $142(65,1 \%)$ & $41(18,8 \%)$ & $21(9,6 \%)$ & $12(5,5 \%)$ & $2(0,9 \%)$ \\
\hline & & 2 & $136(62,4 \%)$ & $36(16,5 \%)$ & $25(11,5 \%)$ & $19(8,7 \%)$ & $2(0,9 \%)$ \\
\hline \multirow[t]{2}{*}{ Domain 7} & $1,17(1,68)$ & 1 & $146(67,0 \%)$ & $33(15,1 \%)$ & $27(12,4 \%)$ & $7(3,2 \%)$ & $5(2,3 \%)$ \\
\hline & & 2 & $140(64,2 \%)$ & $40(18,3 \%)$ & $27(12,4 \%)$ & $10(4,6 \%)$ & $1(0,5 \%)$ \\
\hline
\end{tabular}

$0=$ tidak pernah, 1 = hampir tidak pernah, 2 = kadang-kadang, $3=$ cukup sering, $4=$ sangat sering 
Tabel 5 Hubungan antara indeks DMF-T dengan OHIP-14 pada manula dengan nilai koefisien korelasi Pearson (r)

\begin{tabular}{ccccccccc}
\hline \multirow{2}{*}{ Indeks DMF-T } & \multicolumn{7}{c}{ Indeks } & OHIP-14 \\
\cline { 2 - 9 } & Domain 1 & Domain 2 & Domain 3 & Domain 4 & Domain 5 & Domain 6 & Domain 7 & Total \\
\hline Decay & 0,016 & 0,064 & 0,112 & 0,088 & 0,129 & $0,155^{*}$ & 0,126 & 0,126 \\
Missing & 0,091 & $-0,035$ & 0,084 & $0,155^{*}$ & $0,142^{*}$ & 0,074 & $0,186^{*}$ & 0,131 \\
Filling & $-0,038$ & $-0,036$ & 0,005 & $-0,022$ & 0,025 & $-0,002$ & $-0,061$ & $-0,026$ \\
skor DMF-T & 0,086 & $-0,004$ & 0,124 & $0,175^{*}$ & $0,183^{*}$ & $0,133^{*}$ & $0,219^{*}$ & $0,170^{*}$ \\
\hline
\end{tabular}

* bermakna $(\mathrm{p}<0,05)$

perempuan lebih banyak dibanding laki-laki karena perempuan biasanya lebih peduli pada kesehatan gigi dengan seringnya datang ke tempatpelayanan gigi. ${ }^{11}$

Indeks rata-rata DMF-T pada penelitian ini adalah 11,11. Hasil ini serupa dengan yang dilaporkan oleh Wangsarahardja dkk dengan indeks rata-rata DMF-T berdasarkan dua kategori usia; kategori pertama 14,99 dan kategori kedua 15,24. ${ }^{5}$ Namun hasil ini lebih tinggi dibandingkan yang dilaporkan oleh Ingle dkk, bahwa indeks rata-rata DMF-T sebesar $5,2 .{ }^{10}$ Kemiripan dan perbedaan ini mungkin karena daerah tempat tinggalnya yang kekurangan fasilitas layanan kesehatan khususnya, kesehatan gigi dan mulut,kurangnya perhatian dan ketiadaan biayauntuk mencari dan mendapatkan layanan kesehatan gigi mulut. Hal itu mengakibatkan kurangnya perhatian tentang kesehatan gigi mulut, bahkan terabaikan.

Pada penelitian ini diuji hubungan jenis kelamin dengan nilai DMF-T pada setiap individu, yang hasilnya tidak bermakna $(p=0,321)$. Hal tersebut serupa dengan hasil penelitian yang dilaporkan oleh Wangsarahardja dkk, bahwa tidak didapatkan hasil yang bermakna $(p=0,378)$ mengenai hubungan antara jenis kelamin dengan nilai DMF-T. ${ }^{5}$ Hal tersebut mungkin disebabkannilairata-rata DMF-T pada lakilaki dan perempuan hampir sama besar, sehingga hasil yang diperoleh tidak bermakna.

Pada uji hubungan usia dengan nilai DMF-T, diketahui bahwa usia secara bermakna $(p=0,000)$ berkorelasi positif $(r=0,261)$ dengan nilai DMF-T, yang artinya semakin bertambah usia semakin tinggi pula nilai DMF-T seseorang. Meskipun demikian hasil inimenunjukkan korelasiyanglemah. Pengujian berdasarkan hubungan jumlah gigi dengan DMF-T menunjukkan hasil bermakna $(\mathrm{p}=0,000)$ berkorelasi negatif $(r=-0,591)$ antara jumlah gigi yang dimiliki oleh setiap responden dengan nilai DMF-T.

Dalampenelitian ini tidak didapatkan perbedaan yang bermakna $(\mathrm{p}=0,865)$ antarajenis kelamin dengan skor OHIP-14. Hasil ini sesuai dengan data dari Dahl dkk, bahwa tidak ada perbedaan yang bermakna ( $p$ $=0,51$ ) antara jenis kelamin dengan skor OHIP-14. ${ }^{7}$
Sedangkan jumlah gigi secara bermakna $(\mathrm{p}=0,039)$ berkorelasi negatif $(r=-0,140)$ dengan skor OHIP-14. Hasil ini sesuai dengan yang dilaporkan oleh Dahl $\mathrm{dkk}$, bahwa jumlah gigi secara bermakna $(\mathrm{p}=0,03)$ memiliki korelasi dengan skor OHIP-14; bahwa rata-rata skor OHIP-14 yang semakin rendah pada jumlah gigi yang lebih banyak. Menurutnya kualitas hidup salah satunya dipengaruhi oleh jumlah gigi yang tersisa; semakin banyak jumlah gigi yang ada, maka skor OHI-14 menjadi lebih rendah dibanding dengan yang memiliki gigi lebih sedikit. ${ }^{7}$

Terlihat bahwa skor DMF-T secara bermakna berkorelasi positif $(r=0,170)$ dengan OHIP-14. Hasil ini sesuai dengan data Wangsarahardja dkk, bahwa terjadi hubungan yang bermakna dengan korelasi positif $(r=0,135)$ antara status kesehatan gigi dan mulut dengan kualitas hidup manula. ${ }^{5}$ Namun hasil berbeda dilaporkan oleh Ingle dkk, bahwa tidak terjadi hubungan yang bermakna diantara keduanya. ${ }^{10}$ Menurut Locker yang dikutip oleh Wangsarahardja dkk, dijelaskan bahwaindikator kualitas hidup dalam kaitannya dengan kesehatan mulut menggunakan pengukuran seberapa besar masalah gigi dan mulut mempengaruhi fungsi normal kehidupan seseorang. Penelitian Biazevic dkk di Brazil yang dikutip oleh Wangsarahardja dkk, yang menggunakan OHIP-14 untukmenelitikualitas hidup dalam kaitannyadengan kesehatan mulut. Akibat dari edentulisme, karies, penyakit periodontal, ditambah dengan akibat komorbiditas seperti diabetes dan serostomia, sangat dirasakan oleh manula dan memberikan akibat yang bermakna terhadap fisik, ekonomis, dan psikologis. Akibat dari penyakit oral yang berdampak kepada kualitas hidup manula meliputi berbagai keadaan termasuk mengunyah dan bicara. Selanjutnya dapat memberikan dampak berupa menurunnya interaksi sosial,rasa sejahtera, harga diri dan perasaan berguna. ${ }^{5}$

Statuskesehatan gigi mulut, dalam hal ini DMF-T, secara bermakna berkorelasi positif dengan kualitas hidup, dalam hal ini OHIP-14, dengan nilai korelasi 0,170, disimpulkan bahwa semakin tinggi nilai DMF$\mathrm{T}$ semakin mempengaruhi kualitas hidup manula.

\section{DAFTAR PUSTAKA}

1. Anonim. Kesehatan jiwa pada lanjut usia. Available from:URL:http://74.125.153.132/search?q=cache:Gw2MIDx LTwgJ:www.lenterabiru.com/2010/01/masalah-kesehatan-jiwa-pada-lanjutusia.htm+kondisi+psikologis+lansia\& $\mathrm{cd}=10 \& \mathrm{hl}=\mathrm{id} \& \mathrm{ct}=\mathrm{clnk} \& \mathrm{gl}=\mathrm{id}$. Accessed: 30 Maret 2010 
2. Carey JR. Life span: a conceptual overview. New York: Population Council; 2003. p.8

3. Carranza FA. Glickman's clinical periodontology. $7^{\text {th }}$ Ed. Philadelphia: WB Saunders Company; 1990.p.587-90

4. Hartini R. Available from:http://www.damandiri.or.id/file/ratnasuhartiniunairbab1.pdf. Accessed 2 April 2010.

5. Wangsarahardja K, Dharmawan OV, Kasim E. Hubungan antara status kesehatan mulut dan kualitas hidup pada lanjut usia. Jurnal Universa Medicina 2007; 26: 186-94

6. Anonim. Apa saja yang berubah di gigi dan mulut. Available from: http://bataviase.co.id/detailberita-10495930. html. Accessed: 2 April 2010

7. Dahl KE, Wan NJ, Holst D, Ohrm K. Oral health-related quality of life among adults 68-77 years old in NordTrondelag, Norway. Int J Dent Hygiene 2011; 9: 87-92

8. Hutauruk C. Perawatan gigi terpadu untuk lansia (Gerodontology). Jakarta: EGC; 2006

9. Badan Pusat Statistik Kabupaten Luwu Timur. Kecamatan Malili dalam angka 2008

10. Alamsyah RM, Situmorang N. Dampak gigi molar tiga mandibula impaksi terhadap kualitas hidup mahasiswa Universitas Sumatra Utara. Dentika Dent J 2005; 10 (2): 73-8

11. Ingle NA, Chaly PE, Zohara CK. Oral health related quality of life in adult population attending the outpatient department of a hospital in Chennai, India. J Int Oral Health 2010; 2 (4): 45-56 